\title{
Research on the Guidance of Design to Consumer Desire
}

\author{
Ziyuan Wang ${ }^{1, *}$ \\ ${ }^{1}$ College of Art and Design, Wuhan Textile University, Wuhan, Hubei 430073, China \\ *Corresponding author. Email:1332448994@qq.com
}

\begin{abstract}
Design depends on people's needs. As society develops, people's needs are also changing. With the improvement of material living standards, people pay more attention to psychological and spiritual needs. At the same time, the design of today's products is also affecting people's needs, people's values, non-material needs, and consumer desires. This article will explore the relationship between design and consumer desire from the perspective of design. Design outside of commodities is the manifestation of people's needs and desires. Products are the microcosm of people's lives in an era. It reflects the public's values, needs, and consumer desires, but design meets people's needs while at the same time. How to guide people's desire to consume is what needs to be considered and summarized when designing products.
\end{abstract}

Keywords: Product design, Consumer desire, Desire guidance.

\section{INTRODUCTION}

The core of design is "people", and the purpose of design itself is to meet people's needs, including physical needs, psychological needs, etc. While design meets people's needs, it also stimulates people's certain desires. The design of products can arouse people's various desires, and the desire mentioned in this article refers to the desire for consumption. The desire for consumption is the direct motive that causes consumers to select and purchase products. Therefore, the research on the desire for consumption is more conducive to the design of products to catch people's desire, to make the product targeted to meet and guide people's consumer desire.

Design endows products with function and beauty, allowing people to have a unique impression of objects. Design builds a bridge between the user and the product, allowing the two to interact with each other. It is the medium between the product and the person. Design is a comprehensive skill involving many other disciplines. It exists in all aspects of people's lives. However, consumer desire is not a consumer behavior. Behavior is a complete action, and desire is fragmented but has a long-term impact. Sometimes, although people have desires, they may not have consumptive behaviors, but this desire may occur in the future, or influence the occurrence of others' consumptive behaviors.

Today's product design must not only have the characteristic, such as elegant modeling, high-tech use, and advanced materials, but also pay attention to the design concept and the impact it wants to achieve. Today, with the rapid rise of material living standards, the focus of people's desire to consume is constantly shifting to the inner part of the product. The product is a microcosm of the needs of the contemporary people. What it reflects is the value of the masses. However, how to meet people's needs while guiding people's desire for consumption is what needs to be considered and summarized when designing products.

\section{CONSUMER DESIRE}

Consumer desire can cause consumers to purchase and direct the behavior to a certain product to meet a certain demand of consumers.

To generate desire, there are two prerequisites. The first is the sense of dissatisfaction caused by "demand" and the feeling of "expectation". These are the external factors that form desire and come from the physical and psychological needs of people. The second is the stimulation of the 
external environment to people. The stimulation of psychology and external factors makes people desire, and the desire is mainly controlled by psychology. All in all, people's psychological needs are mainly in material, and psychological needs are in spirit, but psychology and physiology influence each other and make up for each other. It is like buying a product. The purpose is to meet the material needs of consumers. However, in the process of consumption and use, psychological pleasure can also be obtained. On the contrary, the satisfaction of psychological needs can also be balanced by meeting the material needs.

Desire is a complicated process from its generation to its development. Producing is a process from physiology to psychology, and its development is a process from psychology to physiology to psychology again. This process stimulates conduction through physiological mechanisms, regulates positioning by psychological mechanisms, and guides behavioral goals. Ultimately, a common balance between physiology and psychology can be achieved.

\section{THE RELATIONSHIP BETWEEN PRODUCT DESIGN AND CONSUMER DESIRE}

The same is true in a consumer society. At the beginning, people's original intention to buy goods was for material needs, and then they would have psychological feelings. But today, as people's lives are constantly improving, Chinese design is also gradually developing. Many products today have begun to show Chinese traditional culture. Cultural and creative products related to Chinese traditional culture and the spiritual and cultural needs of Chinese consumers are also increasing. Therefore, the use of "symbolic stimulation" is one of the ways to increase the value of goods. This has also led to the gradual shift of consumers' needs to nonmaterial needs. This is also the "external cause" mentioned above. Now the market is expanding. Merchants begin to take advantage of this in order to make greater profits. Therefore, there are a lot of negative effects, such as "gradual abolition of design", etc., the reduced use of products value, and "blindly consuming" and "impulsively consuming". This is what the author believes that today's product design needs to be revised.

In China, due to the late development of Chinese modern design, most of them are still in the stage of imitating and learning Western design. From the current point of view, MIUI products have been relatively successful, especially in household products. The concept of simplicity, warmth and practicality has penetrated into the hearts of every consumer, attracting thousands of consumers. In the process, MIUI products are also gradually changing, and the innovation is to add something new on the original basis. Therefore, it will not make consumers feel the same, and will not make consumers feel unfamiliar with new things. People are inherently contradictory creatures. They look forward to having something different from that of others, and they cannot give up the sense of security that they want to be consistent with everyone. What MIUI does at this point is still very adaptable to the tastes of consumers.

In foreign countries, in product design, a typical example is the streamlined design in the 30s and 40s. Why it become popular with consumers, but it did quickly disappeared in the design field and product market. The reason is that streamlined design is used in various products, and even developed to override the functions of their products. Designers ignore the human instinct to seek new ideas. Even if the "popular" things are beautiful, they cannot be popular forever. Why has "streamlined" design been quietly favored in recent years after nearly 50 years of silence? The reason is that the younger generation has never seen it before the 1950s, and the older generation has nostalgic feelings of all kinds of straight and angular shapes for a long time. More importantly, the designer has learned a lesson. The new streamline is no longer abused, and it is no longer a repetition of the old streamline. It pays more attention to the sense of the times and personalization. In the relationship between function and form beauty, a more correct treatment has been made. Nowadays, many entrepreneurs in the West often set the production cycle of new products in a relatively short period of time in product planning, development and design. Even if the market sales momentum of the product has not fallen, they still do not hesitate to invest heavily in the design and development of newer varieties. The key is that they realize the law of demand and desire, and feel the pulse of consumers. They understand that there is no market if there is no desire to consume. Design depends on consumption and exists, but design guides and promotes consumption.

In general, the factors affecting consumer desire are becoming more and more complex. Affected by the epidemic, online live-streaming e-commerce has developed rapidly. Because of its huge profits, many people obviously have joined it, which has 
made the sales of products increase. Of course, this will also produce impulsive consumption and blind consumption. The recent fact of pouring milk is a typical example. Therefore, in a market environment where there are many problems such as obvious endorsement products and consumers who are their fans blindly consuming to support idols and big sticks, the value and price of the designed products change from being equal to unequal, which in turn triggers a phenomenon in which commodity prices deviate greatly from their values.

In the author's opinion, no matter what kind of problems and functions the products designed by designers need to solve, the key to evaluating the success of the design of this product is ultimately to see whether it can stimulate consumers' desire for consumption and guide consumers to reach the expected effect. Finally, consumer buys and repurchases the product. The longer this impact on consumers lasts, the wider the scope and the more successful the product design will be. Product refers to the consumption orientation. And different consumers will have different psychological reactions when they see the same product. This kind of psychological translation stimulates consumers to produce or elicit their potential consumption desires, and the stimulation of consumer psychology and the generation of consumption desires change with the change of their social value perception. Therefore, the design and expected effect of the product should be combined with the geographical characteristics and cultural background of the product sold.

\section{GUIDING DESIRE}

\subsection{Adjusting Measures to Local Conditions}

What is rational is actual and what is actual is rational. People may feel unacceptable when viewing many products alone, but it is very suitable to place them in the environment that belongs to it. Designers can bring different things to users through vision, touch, smell, etc. The user experience blends with the previous experience to produce a special experience for the product. Therefore, a large part of people's desire to consume comes from the environment, regional culture, and growth background in which they live. The research on this background is the most important part of the pre-investigation in the design of a product. Only by fully investigating the background of users and grasping the physiological and psychological needs of users, can designers stimulate consumers to have a strong desire to buy products. Adding subtle changes in the design can guide consumers to achieve the effect of desire changes in the future. The following are some contents that can better stimulate and guide consumer desire in the preliminary work of the design.

\subsubsection{Form}

Form determines function. In fact, the process of establishing relationships between people and objects is the same as making friends with people. The first impression is very important. Product modelling, color, material, etc. of these things are the first batch of information that consumers can get, and the story and the cultural connotation of the product need consumers to experience. Without a good form, consumers may lose the desire to buy. Therefore, a good product must be impressive, and arouse consumers to further explore, so as to further guide the consumer's desire.

\subsubsection{Cultural Stories}

There is a saying that people live together because they believe in the same story. A product is the epitome of the life of an era, and people of this era are in the same story. The culture contained in the product, such as brand, information, and language, can bring consumers a different experience, and such an experience also differentiates the product from others, allowing consumers to quickly distinguish other products. Consumers are also inspired and guided by products in the process of making such choice.

\subsubsection{Personal Independence of Conduct}

The strengthening feature is what every designer needs to do. By means of amplification and exaggeration, the typical characteristics of the product are presented to consumers, and the desire for expression of the product is clarified, so that the consumers can understand at a glance, which will effectively alleviate the hesitation of consumers in the selection, stimulate the formation of consumer desire.

\subsection{Expected Impact}

A product can be regarded as a miniature of social culture, such as culture, life and economy of 
a nation or a region. Therefore, the product of a region has its unique cultural connotation and value. Products flow in the market, so they will follow the market most. The motive force of promoting the progress of commodities is from market competition, and market competition will inevitably stimulate consumption. Therefore, when designing the products, it is necessary to consider the relationship between the commodity value and the cultural value after satisfying the use function and integrating into the culture. Meanwhile, it is required to combine with the commodity value and guide consumers' positive desire to consume. In this way, the cultural and economic harmony of the consumer society can be achieved.

\section{CONCLUSION}

The exterior and connotation of a product is not only the interpretation of a company's culture and designer's observation and thinking of the environment and society, but also the embodiment of a society and a living state. Design connects culture and function with the heart of consumers through products, which leads to the resonance of consumers in physiology and psychology. This force connects consumers and products firmly and closely, so that the products can get a place on the field. Design plays a positive role in stimulating consumers, guides positive consumption desire, and improves the promotion of more other values of goods.

Since the development of design, its direction and focus have changed greatly with culture and history. The fact of stimulating consumption desire for economic benefits has already violated the original intention of "people-oriented" design, which will not only make consumers feel tired, but also waste resources. When designing a product, designers should focus on the future, guide consumers' desire to buy later from within, and this influence will benefit consumers for life And then, consumers no longer have difficulties in choosing, make clear and firm their own needs, create a good consumption environment in the future, and promote the development of economy and culture.

\section{AUTHORS' CONTRIBUTIONS}

This paper is independently completed by Ziyuan Wang.

\section{REFERENCES}

[1] DaiSato. Solving problems with design [M]. Beijing: Beijing Times Chinese Press, 2016, 48. (in Chinese)

[2] Xiao Di. How to design "consumption desire" [J]. Popular Literature and Art, 2016, 4, 15. (in Chinese)

[3] Yuan Yanzai. Design [M]. Jinan: Shandong People's Publishing House, 2006, 134. (in Chinese)

[4] Li Bizhen. The value composition and value realization of creative commodities [J]. Contemporary Economic Research, 2007(9): 33-36. (in Chinese)

[5] Ma Lan, Ju Wei. Value potential in industrial design [J]. Decoration, 2004(7): 21. (in Chinese)

[6] Duan Xingyu. Analysis of Industrial Design Image Inspiring Consumer Desire [J]. Journal of Nanjing University of the Arts (Fine Arts and Design Edition), 2015(4). (in Chinese)

[7] Liao Hui. Reflection on Design Philosophy in a Consumer Society [J]. Industrial Design, 2018(3):119-120. (in Chinese) 